\title{
Comparison Robotic versus laparoscopic partial nephrectomy for Complex Renal Tumors (with a RENAL nephrometry score $\geq 7$ ): a meta-analysis
}

\author{
Xin Xiao \\ Huzhou Central Hospital \\ Fu-Sheng Peng \\ Huzhou Central Hospital \\ Tian-Li Shi \\ Huzhou Central Hospital \\ Xiao-Hui Huang \\ Huzhou Central hospital \\ Jin-Biao Zhou \\ Huzhou Central Hospital \\ Peng Li \\ Huzhou Central Hospital
}

Yu-Li Jiang ( $\square$ renren108@126.com)

Hangzhou Normal University Hangzhou School of Medicine https://orcid.org/0000-0001-9270-7609

\section{Research}

Keywords: Robotic nephrectomy, laparoscopic partial nephrectomy, renal tumors, RENAL nephrometry score

Posted Date: October 19th, 2020

DOl: https://doi.org/10.21203/rs.3.rs-90761/v1

License: (-) (i) This work is licensed under a Creative Commons Attribution 4.0 International License. Read Full License 


\section{Abstract}

\section{Background}

To compare the perioperative outcomes of Robotic partial nephrectomy (RPN) versus laparoscopic partial nephrectomy (LPN).

\section{Methods}

We searched PubMed, EMBASE and the Cochrane Central Register for studies from 2000 to 2020 to evaluate the perioperative outcomes RPN and LPN in patients with a RENALnephrometry score $\geq 7$. We used RevMan 5.2 to pool the data.

\section{Results}

Seven studies were acquired in our study. No significant differences were found in the estimated blood loss (WMD: WMD: 34.49, 95\% Cl -75.16-144.14, $\mathrm{p}=0.54)$, hospital stay (WMD: $-0.5995 \% \mathrm{Cl}-1.24-0.06, \mathrm{p}=0.07)$, operating time (WMD: $-22.45,95 \% \mathrm{Cl}$ : -35.06 to-9.85, ), postive surgical margin (OR: 0.85, 95\% $\mathrm{Cl} 0.65-1.11, \mathrm{p}=0.23$ ) and transfusion (OR: $0.72,95 \% \mathrm{Cl} 0.48-1.08, \mathrm{p}=0.11$ ). between the two groups. RPN get better outcomes in postoperative renal function (WMD: 3.32, 95\% Cl 0.73-5.91, p=0.01), warm ischenia time (WMD: -6.96, 95\% Cl-7.30--6.62, p <0.0001), conversion( OR: 0.34, 95\%Cl: 0.17 to 0.66, $\mathrm{p}=0.002$ ) and intraoperative complication (OR: $0.52,95 \% \mathrm{Cl} 0.28-0.97, \mathrm{p}=0.04)$.

\section{Conclusion}

RPN could get better perioerative clinical outcomes than LPN for treatment of Complex Renal Tumors( with a RENALnephrometry score $\geq 7$ ).

\section{Background}

Partial nephrectomy (PN) or Nephron-sparing Surgery (NSS) has widely be regarded as the gold standard of surgical stragety for clinical T1 renal tumors [1] NSS can acquire equivalent oncologic outcomes and better postoperative renal function compared to those of radical nephrectomy. In 1993 , Gill et al. firstly introduced laparoscopic partial nephrectomy (LPN) in patients with a single renal tumor[2]. LPN has the advantage of reaching similar oncological outcomes, shorter length of hospital stay and lower estimated blood loss. So, LPN has been widely used for small renal tumors during the past decades[24]. Despite the population of LPN techniques, there were also several limitations, including technical demanding intracorporeal sutured reconstruction skills and difficulty of tumour excision[5].

Robot-assisted partial nephrectomy was firstly reported in 2004, it has become a popular surgical method to clinical T1 renal tumors. The main advantages of the da Vinci® Surgical system consisting of the three-dimensional high-definition vision of the surgical field, a great range of wristed instruments, higher precision in the surgical dissection and easier for intracorporeal sutured reconstruction made RPN more popular than LPN[5-7].

Several meta-analyses had reported two surgical methods for renal tumors[8-10]. Aboumarzouk et al. performed a meta-analysis including 717 patients comparing robotic partial nephrectomy (RPN) with laparoscopic partial nephrectomy (LPN). They found that RPN could be a safe and feasible option as regard to LPN[8]. Choi et al. conducted a meta-analysis included 23 studies involving 2240 patients found that RPN acquire better recovery of postoperative renal function and lower rate of conversion rate to radical nephrectomy[10]. However, no meta-analysis has performed for comparing the RPN and LPN for treatment of complex renal tumors with RENAL nephrometry score $\geq 7$. The aim of this meta-analysis was to perioperative, postoperative renal functional outcomes

And oncological outcomes between RPN and LPN for complex renal tumors with RENAL nephrometry score $\geq 7$.

\section{Methods}

\section{Search strategy}

We conducted this meta-analysis following the Preferred Reporting Items for Systematic Reviews and MetaAnalysis (PRISMA) guidelines. We relevant studies in PubMed, EMBASE and the Cochrane Central Register published in English between 2000 and 2020. We used the following search terms: "robotic partial nephrectomy (RPN) [MeSH]", "laparoscopic partial nephrectomy (LPN) [MeSH]", "renal tumor* [MeSH]", and"RENAL nephrometry score $\geq 7 *$ OR complex renal tumors *". We also used the combined Boolean operators "AND" or "OR" in the title/abstract.

\section{Inclusion and exclusion criteria}

The inclusion criteria were as follows: (1) comparative study of RPN and LPN for the treatment of renal tumors with RENAL nephrometry score $\geq 7$; (2) studies that contained at least one of the following outcomes: estimated blood loss, length of hospital stay, intraoperative complications, postoperative complications, operative time, conversion rate, positive surgical margin (PSM), transfusion, warm ischemia time, postoperative renal function; (3) follow-up duration longer than 6 months; (4). The exclusion criteria were as follows: (1) case reports, reviews, editorial comments, meeting abstracts and articles without applicable data; (2) studies with insufficient data, such as missing the SD (standard deviation) and could not acquire data;(3) studies that were not comparative and renal tumors with the RENAL score $<7$. The process of identifying relevant studies is summarized in Fig. 1. Two investigators (YLJ and XX) reviewed the articles.

\section{Data extraction}


The two authors extracted data, such as the estimated blood loss, operating time, postive surgical margin, postoperative complications, intraoperative complications, hospital stay, confusion, conversion, postoperative renal function and warm ischemia time. Two reviewers (YLJ and XX) assessed the quality of the included studies.

\section{Statistical analysis}

We used Review Manager Version 5.2 software with the Mantel-Haenszel method (The Cochrane Collaboration, Oxford, UK) to conduct the analysis of the data. We used Cochran's $Q$ to evaluate the heterogeneity; $Q<50 \%$ or $P>0.01$ was showed of little heterogeneity. However, $Q>50 \%$ or $P<0.01$ was associated with heterogeneity. For quantitative data, we used the standard mean difference (SMD) and 95\% confidence interval (CI) or weight mean difference (WMD) and $95 \% \mathrm{Cl}$ to pool continuous data. We used the odds ratio (OR) and $95 \% \mathrm{Cl}$ to calculate binary data. The statistical significance level was 0.05 .

\section{Quality assessment of the included studies}

We used the New-Ottawa Scale (NOS) to evaluate the included studies. The NOS scores were evaluated using a 9-point system. An NOS score of 7 or above is considered as higher quality, and an NOS score of 3 or below was believed to have a lower quality. For RCT, we assessed the risk of bias according to the Cochrane Collabortation handbook, version 5.0. Table 2 shows quality assessment of the included studies.

\section{Results}

Seven studies were involved in our study[1, 7, 11-15]. The literature searching process is summarized in Fig. 1. From the PubMed, EMBASE and the Cochrane Central Register, we acquired 2296 studies. After precise search, we included 245 studies. After further processing, we excluded 104 studies. Finally, 7 studies meet inclusion cretia were included in this meta-analysis.

\section{Operating time}

Our study showed no statistical differences between the RPN group and LPN group ( $n=940,477$ patients in the RPN group, 463 patients in LPN group, WMD: $-22.45,95 \% \mathrm{Cl}:-35.06$ to- $9.85, \mathrm{I}^{2}=85 \% ; \mathrm{p}=0.18$, random-effects model, Fig.2).

\section{Estimated blood loss}

Data of estimated blood loss were avaliable in four studies. No statistically significant difference in estimated blood loss between the RPN and LPN groups ( $n=824,419$ patients were in the RPN group, and 405 patients were in the LPN group, WMD: $34.49,95 \% \mathrm{Cl}-75.16-144.14, p=0.54$, random-effects model, Fig.3).

\section{Warm ischemia time}

The data of warm ischemia time were in four studies. There was a statistically significant difference in warm ischemia time between the RPN and LPN groups ( $\mathrm{n}=824,419$ patients were in the RPN group, and 405 patients were in the LPN group, WMD: $-6.96,95 \% \mathrm{Cl}-7.30--6.62, p<0.0001, \mathrm{I}^{2}=0$, randomeffects model, Fig.4).

\section{Transfusion}

Seven studies reported the transfusion in our meta-analysis. There no statistically significant difference in transfusion between the RPN and LPN groups ( $\mathrm{n}$ $=1307,635$ patients were in the RPN group, 672 patients were in the LPN group, OR: $0.72,95 \% \mathrm{Cl} 0.48-1.08, p=0.11, I^{2}=0$, fixed-effective model, Fig.5).

\section{Conversion}

The pooled data showed that a significant statistical differences between the RPN group and LPN group $\left(n=1132,0 R: 0.34,95 \% C l: 0.17\right.$ to $0.66, I^{2}=53 \%$; $\mathrm{p}=0.002$, fixed-effects model, Fig.6).

\section{Hospital stay}

We included four studies in this study. No statistically significant difference in the hospital stay between the RPN and LPN groups ( $\mathrm{n}=824,419$ patients were in the RPN group, and 405 patients were in the LPN group, WMD: $-0.5995 \% \mathrm{Cl}-1.24-0.06, p=0.07, I^{2}=86 \%$, random-effects model, Fig.7).

\section{Intraoperative complications}

Five studies reported the intraoperative complications. There was a statistical significant difference in the intraoperative complications between the RPN and LPN groups ( $n=1040,527$ patients were in the RPN group, and 513 patients were in the LPN group, OR: $0.52,95 \% \mathrm{Cl} 0.28-0.97, p=0.04, I^{2}=0$, fixed effects model, Fig.8).

\section{Postoperative complications}

Data on postoperative complications were existing in seven studies. There was no statistically significant difference in postoperative complications between the RPN and LPN groups ( $n=1256,635$ patients were in the RPN group, 621 patients were in the LPN group, OR: $0.85,95 \%$ Cl $0.65-1.11, p=0.23, I^{2}=0$, fixedeffective model, Fig.9). 


\section{Postoperative renal function}

Three studies included in our meta-analysis to pool the postoperative renal function. There was a statistically significant difference in the postoperative function between the RPN and LPN groups ( $n=524,235$ patients were in the RPN group, and 289 patients were in the LPN group, WMD: 3.32, 95\% Cl 0.735.91, $p=0.01,\left.\right|^{2}=57$, random-effects model, Fig.10).

\section{Postive surgical margin}

Six studies reported the postive surgical margin. There was no statistically significant difference in the postive surgical margin between the RPN and LPN groups ( $n=1132,573$ patients were in the RPN group, and 559 patients were in the LPN group, OR: $0.69,95 \% \mathrm{Cl} 0.27-1.78, p=0.45, I^{2}=0$, fixed effects model, Fig.11).

\section{Discussion}

This meta-analysis is the first study to compare the perioperative outcomes and postoperative recovery renal function. We found that no significant difference was found in the estimated blood loss, hospital stay, postoperative complication rates, positive surgical margin and transfusion between the RPN and LPN groups. The postoperative renal function, radical to conversion and warm ischemia time were lower in the RPN group than in the LPN group. In our meta-analysis, the pooled data of warm ischemia time indicated that the warm ischemia time in RPN group was shorter than LPN group. Choi et al. reported a similar outcome to us $(p=0.005)[10]$.

As regard to radical to conversion, our meta-analysis found that the RPN group had lower conversion rate than the LPN. However, Aboumarzouk et al conducted a meta-analysis included 717 patients found that the conversion rate had no significant difference between the RPN and LPN group ( $p=0.84$ ). This may be due to different baseline characteristics in different studies.

In our meta-analysis, the patients in RPN group got a better recovery in postoperative renal function than in LPN group. The RPN group showed a low warm ischemia time and a satisfactory postoperative eGFR rate. The postoperative renal function was thought to associated with the duration of warm ischemia time. When the warm ischemia time $>30 \mathrm{~min}$, the postoperative had a evident decrease[16].

In our study, the warm ischemia time was lower in RPN group than LPN group. This could reach a quick renal function recovery. Instead, deng et al performed a study by propensity score-based analysis included 116 patients indicated that the eGFR decrease in baseline was similar between the two groups[11]. It could be deduced that RPN is favorable versus LPN in preserving renal function due to decreased WIT. This may be attributed to using precie handling instruments, three-dimensional magnified vision and precise dissection of the renal pedicle and tumor resection are better conducted with robotic assistance. Kopp et al performed a study to analyze the related factors associated to postoperative renal function after partial nephrectomy. They found that RENAL score could predict estimated glomerular filtration rate and warm ischemia time[17]. In our meta-analysis, the pooled data of warm ischemia time had a high heterogeneity. This may relate to the tumor locations and surgeons had different surgical skills. Recently, Bertolo et al reported a study indicating that different reconstrunction methods could short the ischaemia and operating times[18]. The different suture skills may be the causes of high heterogeneity.

In our meta-analysis, we found that the operative time was shorter in RPN than in LPN group. Choi et al performed a meta-analysis compared the RPN and LPN for treatment of renal tumors[10]. They found that no significant difference between the two groups. This was not consistent with our study.

We found that the intraoperative complications were lower in RPN group compared to LPN group. However, zhang et al found no significant difference between the two groups $(p=0.78)$ [14]. Zhang et al performed a meta-analysis found that the intraoperative complications were had no signicant difference in the two groups[14]. In our study, we involved the patients with a RENAL nephrometry score $\geq 7$ which may the resson of difference from Zhang's study. Besides, the different surgeons have different surgical skill level to RPN or LPN.

This may lead to the difference between the two meta-analyses. Our meta-analysis also found that the positive surgical margin had no significant difference between RPN and LPN ( $p=0.45)$. Similarly, zhang et al performed a meta-analysis finding that no significant difference was existent between RPN and LPN group $(p=0.61)$. Aboumarzouk et al also reported a similar outcome $(p=0.93)$.

In our meta-analysis, we found that the estimated blood loss had no significant difference bo etween RPN and LPN group. Zhang et al also found thant the estimated blood loss had no significant difference between the two groups $(p=0.75)$. This is consistent with our study. However, the high heterogeneity in estimated blood loss probably due to the difference in surgeons familiar to surgical process. However, chang et al also performed a propensity-scorematching study finding that RPN resulted in significantly lower mean estimated blood loss compared with LPN $(P=0.025)[19]$. Several systematic review and meta-analyses reported a similar outcomes[8, 10, 20].

Our study also had several limitations. First, we did not include RCTs. This can lower the evidence of our study. Second, the included studies ahd different RENA scores and this could increase the heterogeneity. Besides, this also could lower the confidence of our meta-analysis. Additionally, the different studies had a range of variable tumor size. We did not balance this data. This could impact on warm ischemia time and postoperative renal function. We did not adjust the common baseline characteristics of patients. The different defenition of nomenclature and functional outcomes could lead to heterogeneity[21]. Third, conducted the oncological outcomes for the sake of data of of overall survival, recurrence free survival and cancer speicfic survival. In our metaanalysis, some studies make a propensity score-based analysis and other did not. This could increase heteroneity. Alimi et al conducted a multicenter study 
involving different surgeons which also increase the heterogeneity. For the high heterogeneity, we did not conduct a sensitive analysis or subgroup analysis. We did not find the causes of high heterogeneity. We compared the perioperative outcomes and postioerative renal function outcome.

\section{Conclusions}

Our meta-analysis showed that RPN can achieve comparable outcomes in estimated blood loss, hospital stay, operating time, postive surgical margin and transfusion. RPN achieve better outcomes in postoperative renal function, warm ischenia time, conversion and intraoperative complication. More RCTs should be performed to clarify the effectiveness of RPN and LPN.

\section{Abbreviations}

RPN: Robotic partial nephrectomy: LPN: laparoscopic partial nephrectomy

ESBL: estimated blood loss; Cl: confidence interval; WMD: weight mean difference; OR: odds ratio;

\section{Declarations}

\section{Ethics approval and consent to participate}

Not applicable.

\section{Consent for publication}

Not applicable.

\section{Availability of data and materials}

All data generated or analyzed during this study are included in this published article.

\section{Competing interests}

The authors declare that they have no competing interests.

\section{Funding}

Not applicable.

\section{Authors Contributions}

YLJ and LP designed the study. YLJ wrote the manuscript. YLJ, XX and PFS analyzed the data. HXH, STL and ZJB searched the articles. All authors read and approved the final manuscript.

\section{Acknowledgements}

Not applicable.

\section{Author details}

${ }^{1}$ Department of Urology, Hu Zhou Central Hospital, Huzhou 313000, Zhejiang Province, China

\section{References}

1. Long JA, Yakoubi R, Lee B, Guillotreau J, Autorino R, Laydner H, et al. Robotic versus laparoscopic partial nephrectomy for complex tumors: comparison of perioperative outcomes. Eur Urol. 2012;61:1257-62.

2. Gill IS, Kavoussi LR, Lane BR, Blute ML, Babineau D, Colombo JR, Jr., et al. Comparison of 1,800 laparoscopic and open partial nephrectomies for single renal tumors. J Urol. 2007;178:41-6.

3. Uzzo RG, Novick AC. Nephron sparing surgery for renal tumors: indications, techniques and outcomes. J Urol. 2001;166:6-18.

4. White MA, Haber GP, Autorino R, Khanna R, Hernandez AV, Forest S, et al. Outcomes of robotic partial nephrectomy for renal masses with nephrometry score of $\geq 7$. Urology. 2011;77:809-13.

5. Rogers CG, Patard JJ. Open to debate. The motion: Robotic partial nephrectomy is better than open partial nephrectomy. Eur Urol. 2009;56:568-70.

6. Buffi NM, Saita A, Lughezzani G, Porter J, Dell'Oglio P, Amparore D, et al. Robot-assisted Partial Nephrectomy for Complex (PADUA Score $\geq 10$ ) Tumors: Techniques and Results from a Multicenter Experience at Four High-volume Centers. Eur Urol. 2020;77:95-100.

7. Gu L, Ma X, Wang B, Xie Y, Li X, Gao Y, et al. Laparoscopic vs robot-assisted partial nephrectomy for renal tumours of $>4$ cm: a propensity score-based analysis. BJU Int. 2018;122:449-55. 
8. Aboumarzouk OM, Stein RJ, Eyraud R, Haber GP, Chlosta PL, Somani BK, et al. Robotic versus laparoscopic partial nephrectomy: a systematic review and meta-analysis. Eur Urol. 2012;62:1023-33.

9. Wu Z, Li M, Liu B, Cai C, Ye H, Lv C, et al. Robotic versus open partial nephrectomy: a systematic review and meta-analysis. PLoS One. $2014 ; 9$ :e94878.

10. Choi JE, You JH, Kim DK, Rha KH, Lee SH. Comparison of perioperative outcomes between robotic and laparoscopic partial nephrectomy: a systematic review and meta-analysis. Eur Urol. 2015;67:891-901.

11. Deng W, Li J, Liu X, Chen L, Liu W, Zhou X, et al. Robot-assisted versus laparoscopic partial nephrectomy for anatomically complex T1b renal tumors with a RENAL nephrometry score $\geq 7$ : A propensity score-based analysis. Cancer Med. 2020;9:586-94.

12. Jang HJ, Song W, Suh YS, Jeong US, Jeon HG, Jeong BC, et al. Comparison of perioperative outcomes of robotic versus laparoscopic partial nephrectomy for complex renal tumors (RENAL nephrometry score of 7 or higher). Korean J Urol. 2014;55:808-13.

13. Wang Y, Ma X, Huang Q, Du Q, Gong H, Shang J, et al. Comparison of robot-assisted and laparoscopic partial nephrectomy for complex renal tumours with a RENAL nephrometry score $\geq 7$ : peri-operative and oncological outcomes. BJU Int. 2016;117:126-30.

14. Zhang S, Lin T, Liu G, Zhang S, Guo H. Comparisons of the safety and effectiveness of robot-assisted versus laparoscopic partial nephrectomy for large angiomyolipomas: a propensity score-matched analysis. Int Urol Nephrol. 2020.

15. Alimi Q, Peyronnet B, Sebe P, Cote JF, Kammerer-Jacquet SF, Khene ZE, et al. Comparison of Short-Term Functional, Oncological, and Perioperative Outcomes Between Laparoscopic and Robotic Partial Nephrectomy Beyond the Learning Curve. J Laparoendosc Adv Surg Tech A. 2018;28:1047-52.

16. Thompson RH, Lane BR, Lohse CM, Leibovich BC, Fergany A, Frank I, et al. Every minute counts when the renal hilum is clamped during partial nephrectomy. Eur Urol. 2010;58:340-5.

17. Kopp RP, Mehrazin R, Palazzi K, Bazzi WM, Patterson AL, Derweesh IH. Factors affecting renal function after open partial nephrectomy-a comparison of clampless and clamped warm ischemic technique. Urology. 2012;80:865-70.

18. Bertolo R, Campi R, Klatte T, Kriegmair MC, Mir MC, Ouzaid I, et al. Suture techniques during laparoscopic and robot-assisted partial nephrectomy: a systematic review and quantitative synthesis of peri-operative outcomes. BJU Int. 2019;123:923-46.

19. Chang KD, Abdel Raheem A, Kim KH, Oh CK, Park SY, Kim YS, et al. Functional and oncological outcomes of open, laparoscopic and robot-assisted partial nephrectomy: a multicentre comparative matched-pair analyses with a median of 5 years' follow-up. BJU Int. 2018;122:618-26.

20. Zhang X, Shen Z, Zhong S, Zhu Z, Wang X, Xu T. Comparison of peri-operative outcomes of robot-assisted vs laparoscopic partial nephrectomy: a metaanalysis. BJU Int. 2013;112:1133-42.

21. Alenezi A, Novara G, Mottrie A, Al-Buheissi S, Karim O. Zero ischaemia partial nephrectomy: a call for standardized nomenclature and functional outcomes. Nat Rev Urol. 2016;13:674-83.

\section{Tables}

Table1 Basic Characteristics of the Included Studies

\begin{tabular}{|c|c|c|c|c|c|c|c|c|}
\hline \multirow[t]{2}{*}{ Study } & \multirow[t]{2}{*}{ Year } & \multirow[t]{2}{*}{ Design } & \multirow{2}{*}{$\begin{array}{l}\text { Sample } \\
\text { Size } \\
\text { RPN LPN }\end{array}$} & \multirow{2}{*}{$\begin{array}{l}\text { Mean } \\
\text { age(years) } \\
\text { RPN LPN }\end{array}$} & \multirow{2}{*}{$\begin{array}{l}\text { Tumor } \\
\text { Size(cm) } \\
\text { RPN LPN }\end{array}$} & $\begin{array}{l}\text { BMI } \\
\left(\mathrm{kg} / \mathrm{m}^{2}\right)\end{array}$ & \multicolumn{2}{|c|}{$\begin{array}{l}\text { RENAL score (sample } \\
\text { size) }\end{array}$} \\
\hline & & & & & & RPN LPN & RPN & LPN \\
\hline Long & 2012 & $\mathrm{P}, \mathrm{S}$ & 199182 & $58.5 \quad 59.5$ & $3.8^{\mathrm{a}} 4.0^{\mathrm{a}}$ & $\begin{array}{l}30.7^{\mathrm{a}} \\
29.2^{\mathrm{a}}\end{array}$ & 8.6 & 8.7 \\
\hline Jang & 2014 & $\mathrm{R}, \mathrm{S}$ & 8938 & $49.1 \quad 54.7$ & $3.0^{\mathrm{a}} 2.5^{\mathrm{a}}$ & $\begin{array}{c}24.3^{\mathrm{a}} \\
25.3^{\mathrm{a}}\end{array}$ & 7.8 & 7.5 \\
\hline Wang & 2015 & $\mathrm{R}, \mathrm{S}$ & 81135 & 61.263 .5 & $\begin{array}{l}3.8^{\mathrm{a}} \\
3.6^{\mathrm{a}}\end{array}$ & $\begin{array}{l}26.2^{b} \\
26.1^{b}\end{array}$ & $8.3^{b}$ & $8.1^{\mathrm{b}}$ \\
\hline $\mathrm{Gu}$ & 2018 & $\mathrm{R}, \mathrm{S}$ & 9696 & $51^{\mathrm{b}} \quad 50^{\mathrm{b}}$ & $4.8^{\mathrm{b}} 4.8^{\mathrm{b}}$ & $\begin{array}{l}25.9^{b} \\
25.6^{b}\end{array}$ & $8^{b}$ & $8^{b}$ \\
\hline Deng & 2020 & $\mathrm{R}, \mathrm{S}$ & 5858 & $52.0 \quad 50.6$ & $\begin{array}{lll}5.0 & 4.9\end{array}$ & NA NA & $8^{b}$ & $8^{b}$ \\
\hline Alimi & 2018 & $\mathrm{P}, \mathrm{M}$ & 5050 & NA NA & 3.94 .1 & NA NA & $7.5^{\mathrm{a}}$ & $7.8^{a}$ \\
\hline $\begin{array}{l}\text { Zhang } \\
2020\end{array}$ & & $\mathrm{R}, \mathrm{S}$ & 6262 & $47 \quad 46$ & NA NA & $26 \quad 25$ & $9^{b}$ & $8^{b}$ \\
\hline
\end{tabular}

$P$ prospective $S$ single center $R$ retrospective $N A$ not avaliable $B M /$ body mass index ${ }^{a}$ Mean ${ }^{b}$ Median M multiple

Table2 Newcastle-Ottawa Scale for risk of bias assessment of the included studies 


\begin{tabular}{|c|c|c|c|c|c|c|c|c|c|c|}
\hline \multirow{2}{*}{$\begin{array}{l}\text { Study } \\
\text { Design }\end{array}$} & & \multicolumn{4}{|l|}{ Selection } & \multirow[t]{2}{*}{ Comparability } & \multicolumn{3}{|l|}{ Outcome } & \multirow[t]{2}{*}{ Total } \\
\hline & & $\begin{array}{l}\text { Representativeness } \\
\text { of exposed cohort }\end{array}$ & $\begin{array}{l}\text { Selective of } \\
\text { nonexposed } \\
\text { Cohort }\end{array}$ & $\begin{array}{l}\text { Ascertainment } \\
\text { of exposure }\end{array}$ & $\begin{array}{l}\text { Outcome } \\
\text { not } \\
\text { present } \\
\text { at start }\end{array}$ & & $\begin{array}{l}\text { Assessment } \\
\text { of outcome }\end{array}$ & $\begin{array}{l}\text { Adequate } \\
\text { follow-up } \\
\text { length }\end{array}$ & $\begin{array}{l}\text { Adequacy } \\
\text { of follow- } \\
\text { up }\end{array}$ & \\
\hline Long & $\mathrm{P}$ & $\star \star$ & ** & & * & & * & * & * & 8 \\
\hline Jang & $\mathrm{R}$ & * & * & * & * & & * & * & * & 7 \\
\hline Wang & $\mathrm{R}$ & * & * & * & * & & * & * & * & 7 \\
\hline $\mathrm{Gu}$ & $\mathrm{R}$ & * & * & * & * & & * & * & * & 7 \\
\hline Deng & $\mathrm{R}$ & * & * & * & * & & * & * & * & 7 \\
\hline Alimi & $\mathrm{P}$ & ** & ** & & * & & * & * & * & 8 \\
\hline Zhang & $\mathrm{P}$ & * & * & & * & & * & * & * & 6 \\
\hline
\end{tabular}

$R$ Respective $P$ Prospective

\section{Figures}

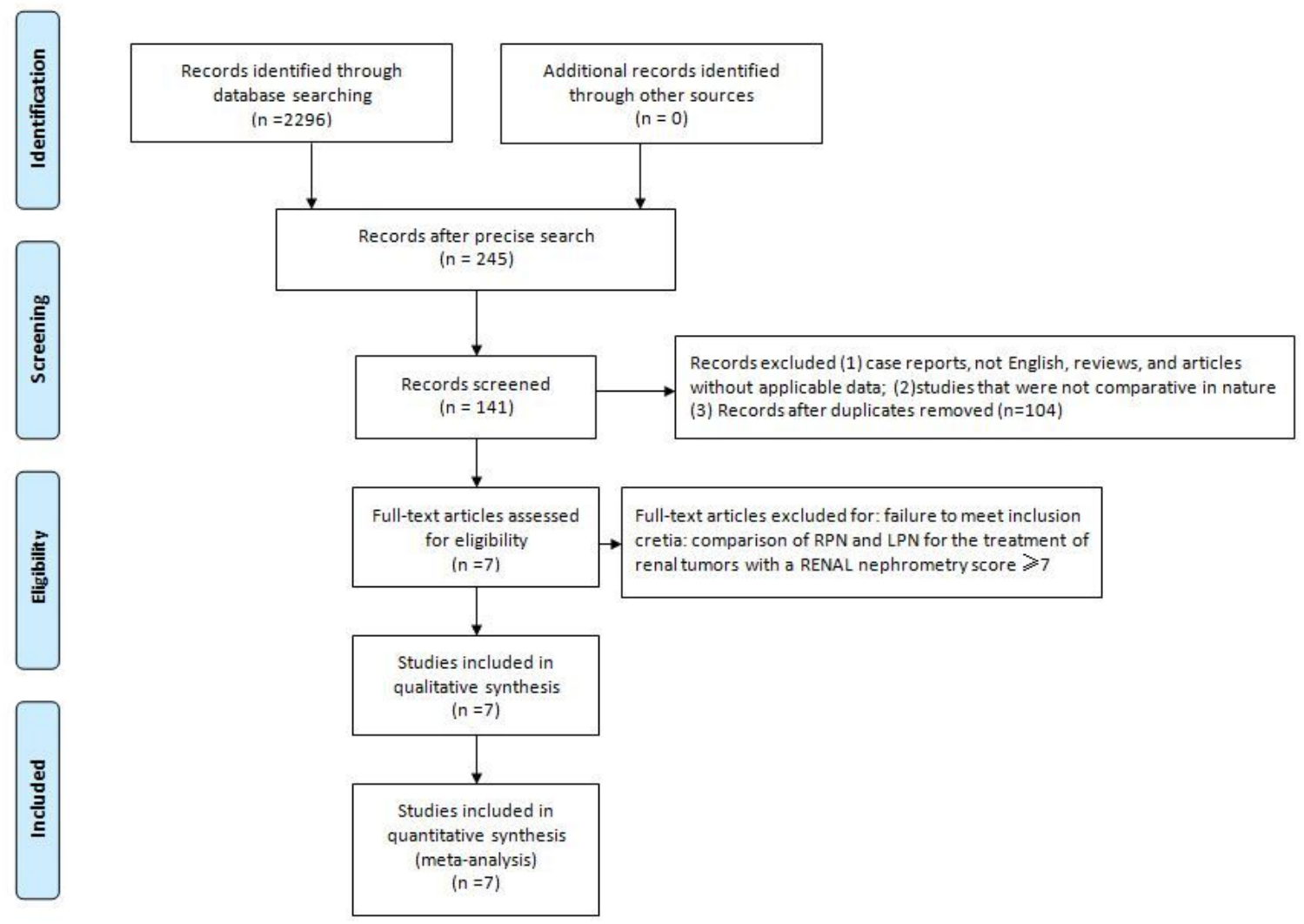

Figure 1

Flow diagram of the process for the selection of relevant studies.

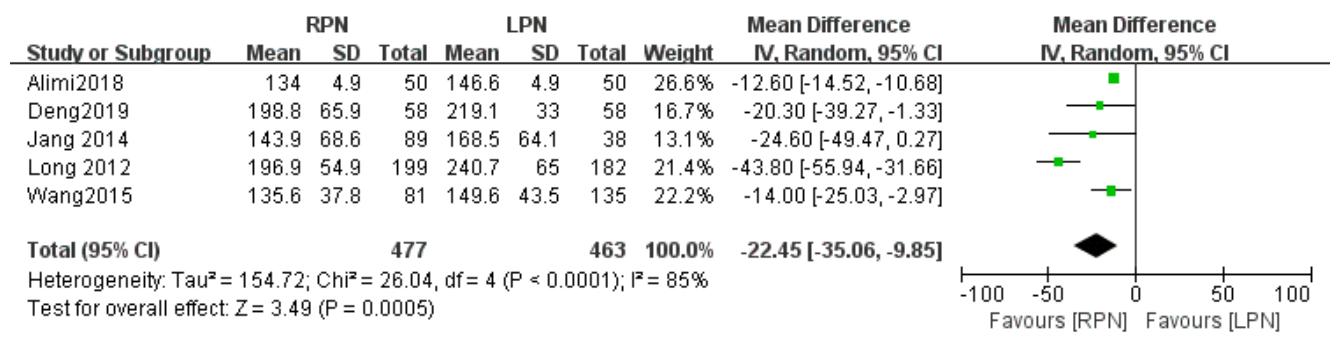

Figure 2 
Forest plot for operating time between the RPN and LPN.

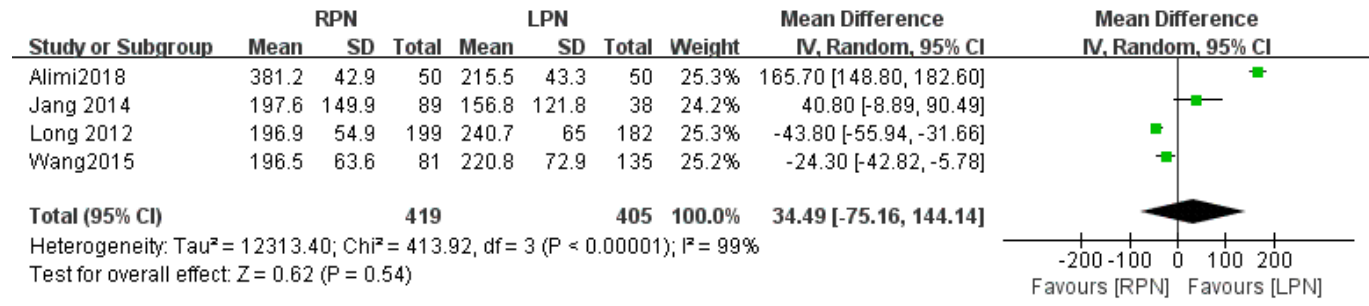

\section{Figure 3}

Forest plot for estimated blood loss between the RPN and LPN.

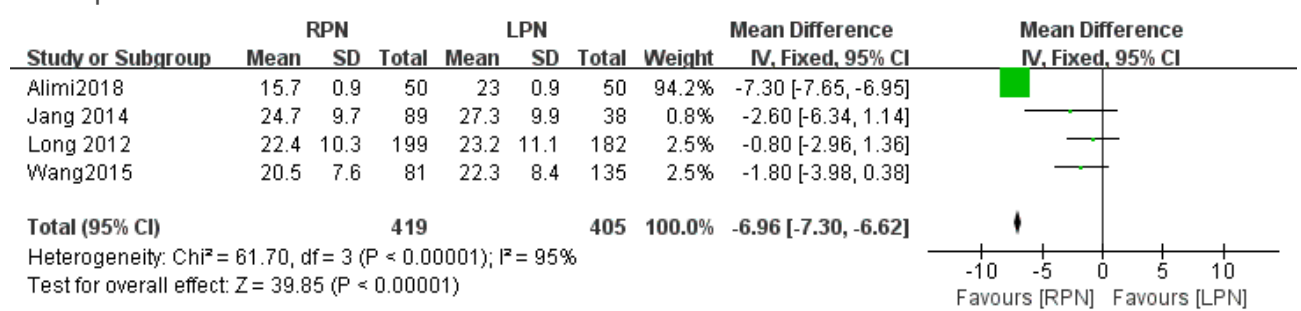

Figure 4

Forest plot for warm ischemia time between the RPN and LPN.

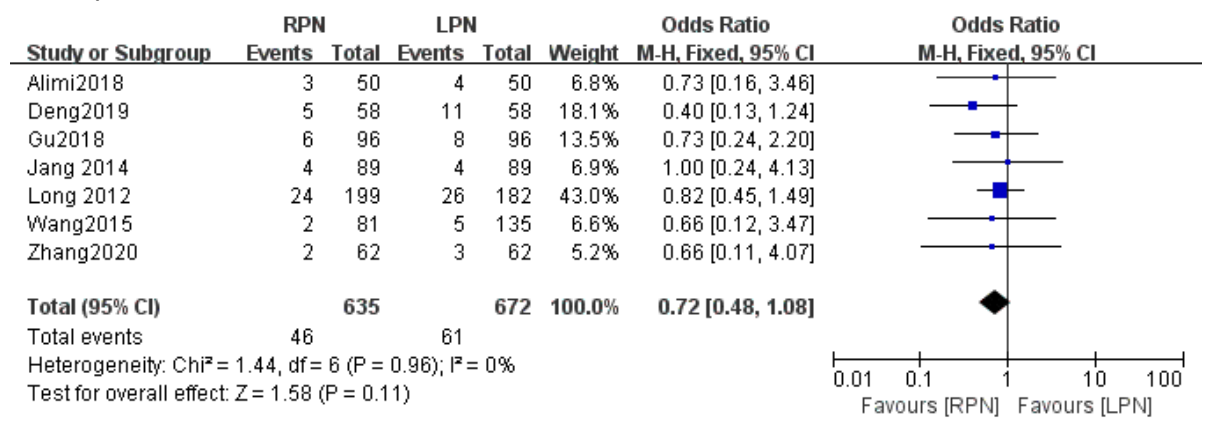

\section{Figure 5}

Forest plot for transfusion between the RPN and LPN.

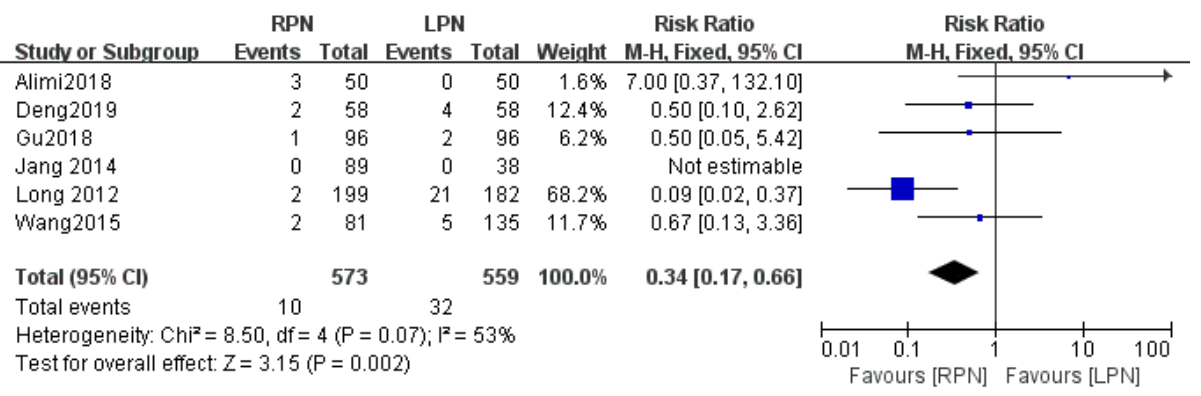

\section{Figure 6}

Forest plot for conversion between the RPN and LPN.

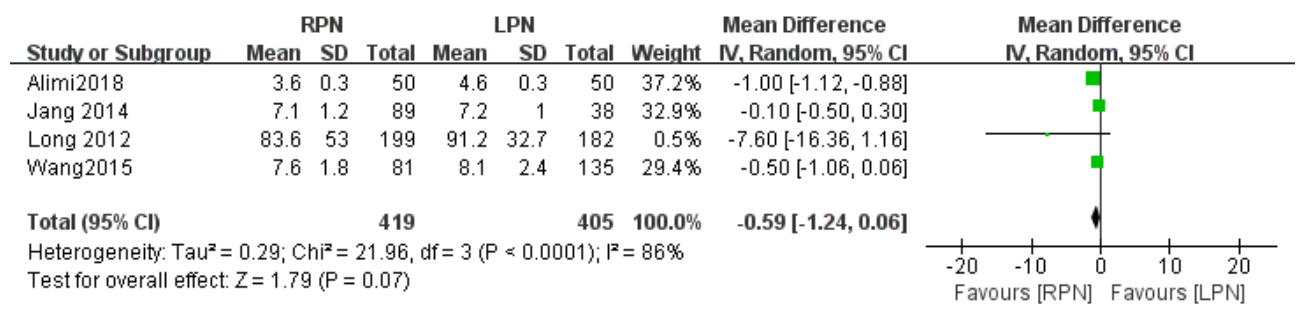


Forest plot for hospital stay between the RPN and LPN.

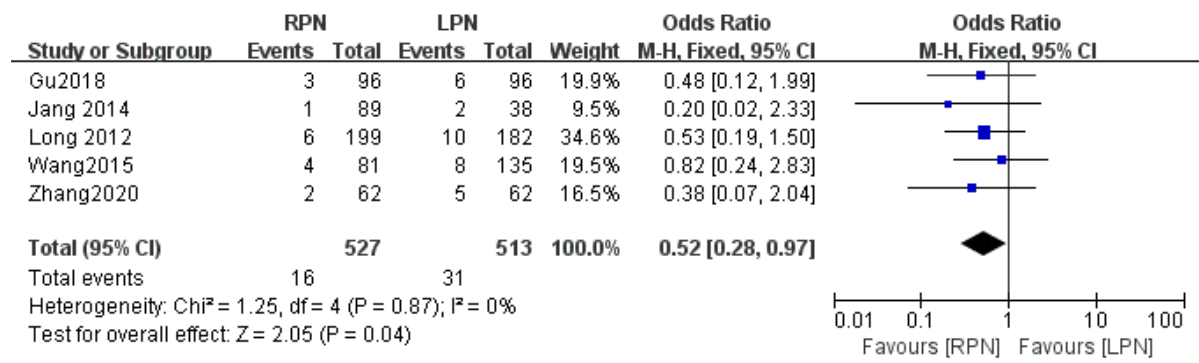

\section{Figure 8}

Forest plot for intraoperative complications between the RPN and LPN.

\begin{tabular}{|c|c|c|c|c|c|c|c|}
\hline Studv or Subgroup & $\begin{array}{c}\text { RPN } \\
\text { Events }\end{array}$ & Total & $\begin{array}{l}\text { LPN } \\
\text { Events }\end{array}$ & Total & Weight & $\begin{array}{c}\text { Odds Ratio } \\
\text { M-H, Fixed, } 95 \% \mathrm{Cl}\end{array}$ & $\begin{array}{c}\text { Odds Ratio } \\
\text { M-H, Fixed, 95\% Cl }\end{array}$ \\
\hline Alimi2018 & 16 & 50 & 19 & 50 & $10.7 \%$ & $0.77[0.34,1.75]$ & \\
\hline Deng2019 & 12 & 58 & 17 & 58 & $11.2 \%$ & $0.63[0.27,1.47]$ & \\
\hline Gu2018 & 18 & 96 & 20 & 96 & $13.5 \%$ & $0.88[0.43,1.79]$ & \\
\hline Jang 2014 & 18 & 89 & 11 & 38 & $10.2 \%$ & $0.62[0.26,1.49]$ & \\
\hline Long 2012 & 64 & 199 & 56 & 182 & $33.0 \%$ & $1.07[0.69,1.64]$ & \\
\hline Wang2015 & 14 & 81 & 30 & 135 & $15.5 \%$ & $0.73[0.36,1.48]$ & \\
\hline Zhang2020 & 7 & 62 & 8 & 62 & $5.9 \%$ & $0.86[0.29,2.53]$ & \\
\hline Total $(95 \% \mathrm{Cl})$ & & 635 & & 621 & $100.0 \%$ & $0.85[0.65,1.11]$ & \\
\hline Total events & 149 & & 161 & & & & \\
\hline \multicolumn{5}{|c|}{$\begin{array}{l}\text { Heterogeneity: } \mathrm{Chi}^{2}=2.27, \mathrm{df}=6(\mathrm{P}=0.89) ; \mathrm{I}^{2}=0 \% \\
\text { Test for overall effect: } Z=1.21(P=0.23)\end{array}$} & & & \begin{tabular}{ccccc} 
& 1 & 1 & 1 \\
0.02 & 0.1 & 1 & 10 & 50 \\
\multicolumn{3}{l|}{ Favours [RPN] } & Favours [LPN]
\end{tabular} \\
\hline
\end{tabular}

\section{Figure 9}

Forest plot for postoperative complications between the RPN and LPN.

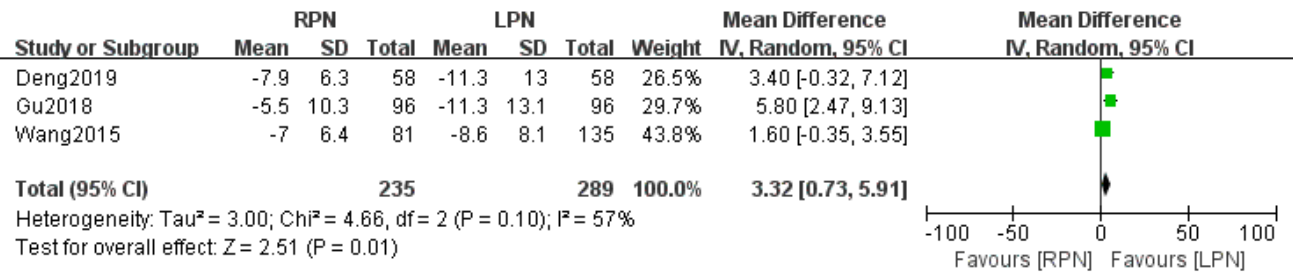

\section{Figure 10}

Forest plot for postoperative renal function between the RPN and LPN.

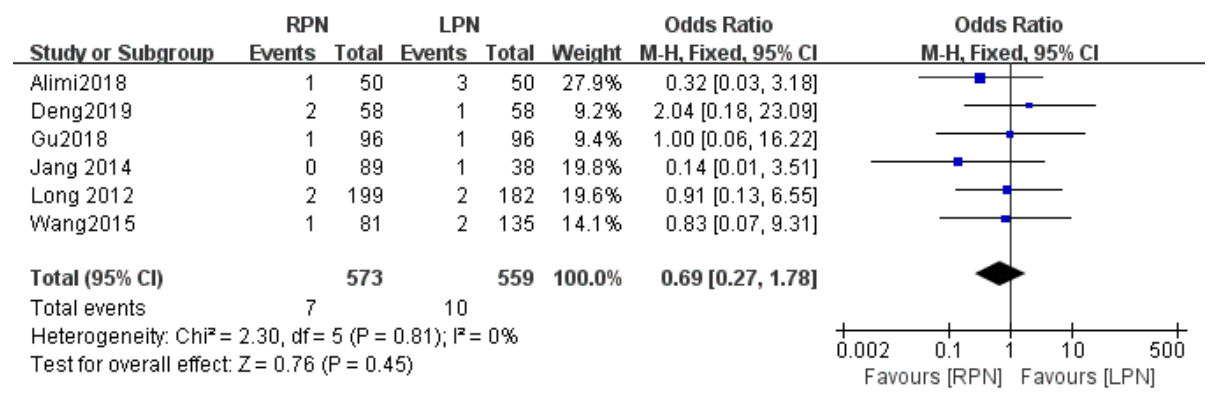

\section{Figure 11}

Forest plot for postive surgical margin between the RPN and LPN. 